\title{
How Do Selected National Funding Agencies Communicate the Concept of Cognitive Innovation on Their Public Website?
}

\author{
Mona Nasser \\ Plymouth University Peninsula Schools of Medicine and Dentistry (PU PSMD), UK \\ mona.nasser@plymouth.ac.uk
}

Received 9 May 2017; accepted 26 September 2017; published 21 November 2017.

\begin{abstract}
In this paper, I discuss how three funding agencies have presented or discussed the concept of cognitive innovation in formulating their research programs, calls or funding opportunities on their website. Gummerum and Denham recognize the association between the innovator, innovation and the contextual challenge of the concept of cognitive innovation and its impact on society (Gummerum \& Denham, 2014). Research funders make decisions to allocate resources to certain research questions and not others. Researchers attempt to understand how these decisions are made and consider them in applying for funding to them. One of the information sources that researchers can use to inform what areas of research they can get funding for or how to formulate their research grants is the public information on the website of the funding agencies. In this paper, I only focus on the information presented on their website and not their internal processes or policies. The approach of funding agencies to present what is categorized as innovation or creativity has the potential to influence how researchers focus or frame their research.
\end{abstract}

Keywords: innovation; research funder; research grant; research system.

Three funding agencies have been included in this paper: NIHR (National Institute for Health Research, UK), ZonMW (The Netherlands Organization for Health Research and Development, the Netherlands) and PCORI (Patient-Centered Outcomes Research Institute, USA). These agencies were identified as champions in dealing with issues of reducing research waste and adding value to research in a previous study (Nasser et al., 2017). This article shows that there is a lack of clarity on their 
website in defining and outlining the concept of innovative or creative in formulating calls for research projects or programs and their underpinning evidence of what leads to innovation. Based on the information available on their website, it seems that some agencies assume that the background and achievements of individual researchers are the main catalysts, others consider collaboration with the industry as a key catalyst, and finally one organization considers developing new methods a key step that can lead to innovation. It was not clear how the organization evaluated and measured whether the strategies worked and were successful.

Gummerum and Denham recognize the association between the innovator, innovation and the contextual challenge of the concept cognitive innovation and its impact on society (Gummerum \& Denham, 2014). Despite the wide use of the term "innovation" to describe certain research projects, only a tiny fraction of research projects are truly disruptively innovative and it has been suggested that the drive for innovation can inappropriately reduce the conduct of replication studies (Ioannidis, 2016; Ioannidis, Boyack, Small, Sorensen, \& Klavans, 2014). Studies tend to deliberately be different in one or other minor aspect to justify getting resources or support to conduct the study.

Research funders make decisions on how to allocate resources to certain research questions and not others. Researchers attempt to understand how these decisions are made and consider them in applying for funding to the funding agencies. One of the information sources that researchers use to inform these decisions is the public information on the website of the research funding agencies. In this paper, I discuss how three funding agencies have presented or discussed the concept of cognitive innovation in formulating their research programs, calls or funding opportunities on their websites. This does not reflect the internal policies of the funding agencies, as I did not conduct in-depth interviews or ethnographies studies for each funding agency. The public information of the funding agency demonstrates the public image of the funding agency and how it might be perceived by researchers.

In a previous project, we conducted an evaluation of the websites of 12 research funders on how they address issues on reducing research waste; three research funders demonstrated the best strategies to manage the issue of reducing research waste and adding value to research: NIHR (UK), ZonMW (the Netherlands), and PCORI (USA), (Nasser et al., 2017). This reflects their commitments to add value to research, ensure that standards of research integrity are met and more evidence based. Therefore, I focused on these three organizations.

\section{The National Institute for Health Research (NIHR)}

NIHR is the key applied health research funder in UK. They expect that researchers work with patients and members of the public in designing and implementing the research projects, and that they demonstrate that the findings can potentially have 
an effect on patient health in a reasonable timeframe. NIHR has a range of programs focusing on different research topics, including health services and delivery research, invention for innovation, health technology assessment (HTA) and public health research. There are two relevant programs on the NIHR website to this evaluation. One is active (invention for innovation; NIHR, 2017a), and one is currently on hold: Research for Innovation Speculation and Creativity (RISC; NIHR, 2017c).

The invention for innovation program is described as translational funding scheme focusing on advances in health care technologies, devices and interventions to increase patient benefit. It focuses on the innovation itself, the context and certain aspects of societal domain (but not the innovators themselves). It describes an invention as something that can increase patient benefit but also be adopted and commercialized. They are further described as two streams-the product development awards and challenge awards - both focusing on technology. Terms like "disruptive" are used to describe them without providing further clarification. The innovator is not discussed in detail beyond the organizations that they are affiliated with. The project requires collaboration between two or more of these organizations (higher education institutes, institutes associated with national health services (NHS), private industry). In the description of the guideline for applicants, they outline six criteria to inform prioritizing allocating resources to a project; one of them is level of innovation. The concept of innovation was described as "how the proposed device, technology or intervention presents a significant level of innovation, providing an advance over currently commercially available products. The application must contain an explanation of how adoption of the technology would change clinical practice and how the project will generate data to drive adoption" (NIHR, 2017b, p. 8). It doesn't describe in this section what they mean by "change clinical practice." They do describe in other sections the issue "increase patient benefit" (which is what they might be referring to).

\section{The Netherlands Organization for Health Research and Development (ZonMW)}

ZonMW's main commissioners are the ministry of health, welfare and sport and the Netherlands Organizations for Scientific Research, so its focus is on projects related to improving health and health care in the Netherlands. The organization not only focuses on conduct of health research but also on implementing research findings. ZonMW has a funding program called Innovative Research Incentives Scheme (Veni; ZonMW, 2016); they say that its focus is "the Veni target group consists of excellent researchers with a striking and original talent as well a considerable fascination for doing challenging and pioneering research. The focus in this respect is on innovative and curiosity-driven research." However, they do not describe the definition of "innovative." 
There are not many details on how they adapted the processes to ensure that creative and innovative projects get prioritized. The calls were open and responsive, not commissioned and pre-defined. Studies intending to identify effective approaches to peer review research grants raised concerns that commissioning research (instead of having open calls) can hinder the creativity and innovation in research base (Staley \& Hanley, 2008). That can explain the choice of this type of research grant call. This research program focuses on the innovator, innovation (although not described in detail how this is defined) and its societal impact.

\section{The Patient-Centered Outcome Research Institute (PCORI)}

PCORI has a legislative mandate "to assist patients, clinicians, purchasers and policy makers in making informed health decision by advancing the quality and relevance of evidence concerning the manner in which diseases, disorders, and other health conditions can effectively and appropriately be prevented, diagnosed, treated, monitored, and managed through research and evidence synthesis that considers variations in patient subpopulations, and the dissemination of research findings with respect to the relative health outcomes, clinical effectiveness, and appropriateness of the medical treatments, services, and [other] items" (PCORI, 2013b, p. 2). They have identified advancement in methodology as key step to be innovative in research. They acknowledge that our current research methods to evaluate health care intervention for patients and community are not optimal and we need innovative and new methods in health services research. They are looking for a new model of research and innovation that introduces a better balance between evidence generation using sound methods and the acceptance and utilization of them. The two key areas that they identified include: (a) developing consensus standards for research, (b) identifying gaps in patient's needs. As part of this concept, they introduced and awarded the PCORI challenge initiative 2013 called the PCORI matchmaking pap challenge. The winner proposed a platform that let users propose, endorse and pledge funds for research question and topics and researchers to apply for funding to conduct studies on the topics that have met their fundraising goals (PCORI, 2013a). These programs primarily focus on the innovation and its context and societal impact.

\section{Conclusions}

This is an overview on examples how these three national research funders communicated the concept of innovation and creativity in their research programs on their websites. The article demonstrates that there is a lack of clarity in defining the concept of innovation and creativity in shaping research grant programs and process and their underlying evidence around it on the websites. There seem to be underlying assumptions regarding what can lead to innovation, although the 
underlying evidence is not always comprehensively reported-assumptions like supporting talented and high-achieving individuals (ZonMw), collaborating with industry (NIHR), or developing new methods can lead to innovation (PCORI). Moreover, it is unclear how the agencies evaluate whether their strategies were successful in achieving innovation or creativity.

This is not a full reflection of how the funding agencies conceptualize innovation and creativity or how researchers perceive it. A lot of internal discussion and policies are not communicated on the website. Researchers engage with staff members of funding agencies and experts in grant applications in universities and research institutes to decide how to formulate research grant applications. An in-depth evaluation including interviews with individuals in the funding agencies and researchers applying to the grant programs along with ethnographic studies on the processes in the funding agencies is required.

\section{Acknowledgments}

I would like to thank Hannah Drayson, Kathryn Francis and Michael Sonne Kristensen for their interesting and relevant responses and comments to my piece and all the participants of the Off the Lip 2017 event for the discussion on the paper.

\section{References}

Gummerum, M., Denham, S. L. (2014). Cognitive innovation: From cell to society. Europe's Journal of Psychology, 10(4), 586-588. doi:10.5964/ejop.v10i4.879

Ioannidis, J. P. A. (2016). The mass production of redundant, misleading, and conflicted systematic reviews and meta-analyses. The Milbank Quarterly, 94(3), 485-514. doi:10.1111/14680009.12210

Ioannidis, J. P. A., Boyack, K. W., Small, H., Sorensen, A. A., \& Klavans, R. (2014). Bibliometrics: Is your most cited work your best? Nature, 514(7524), 561-562. doi:10.1038/514561a

Nasser, M., Clarke, M., Chalmers, I., Brurberg, K. G., Nykvist, H., Lund, H. \& Glasziou, P. (2017). What are funders doing to minimise waste in research? The Lancet, 389(10073), 1006-1007. doi:10.1016/S0140-6736(17)30657-8

NIHR. (2017a). Invention for Innovation. Retrieved November 19, 2017 from https://www.nihr.ac.uk/funding-and-support/funding-for-research-studies/funding-programmes/invention-for-innovation/

NIHR. (2017b). Invention for Innovation (i4i) Challenge Award. Applicant guidance. Retrieved November 19, 2017 from https://www.nihr.ac.uk/funding-and-support/funding-forresearch-studies/funding-programmes/invention-for-innovation/i4iProgrammeGuidance_ChallengeAwards_2017.pdf 
NIHR. (2017c). RISC - Research for Innovation Speculation and Creativity - NIHR. Retrieved November 19, 2017 from http://www.rds-sc.nihr.ac.uk/risc/

PCORI. (2013a). PCORI Challenge Initative - 2013. Retrieved November 19, 2017 from https://www.pcori.org/funding-opportunities/programmatic-funding/pcori-matchmaking-app-challenge/pcori-challenge-0

PCORI. (2013b). Strategic Plan. Retrieved November 19, 2017 from https://www.pcori.org/sites/default/files/PCORI-Strategic-Plan.pdf

Staley, K., \& Hanley, B. (2008). Scoping research priority setting (and the presence of PPI in priority setting) with UK clinical research organisations and funders. Retrieved November 19, 2017 from http://citeseerx.ist.psu.edu/viewdoc/download?doi=10.1.1.462.2185\&rep=rep1\&type=pdf

ZONMW (2016). Innovational Research Incentives Scheme: Veni. Retrieved November 19, 2017 from https://www.nwo.nl/en/funding/our-funding-instruments/nwo/innovational-research-incentives-scheme/veni/index.html 